\title{
Ovarian Steroid Hormone Secretion Activity Examined After Supplementation of Green Tea Extract
}

\author{
S. ROYCHOUDHURY ${ }^{1,2}$, M. HALENAR ${ }^{2}$, V. TUPA $^{2}$, K. MICHALCOVA ${ }^{2}$, S. NATH ${ }^{1}$, \\ M. KACANIOVA ${ }^{3}$, A. KOLESAROVA ${ }^{2}$
}

${ }^{1}$ Department of Life Science and Bioinformatics, Assam University, Silchar, India, ${ }^{2}$ Department of Animal Physiology, Faculty of Biotechnology and Food Sciences, Slovak University of Agriculture in Nitra, Nitra, Slovak Republic, ${ }^{3}$ Department of Microbiology, Faculty of Biotechnology and Food Sciences, Slovak University of Agriculture in Nitra, Nitra, Slovak Republic

Received June 2, 2017

Accepted September 12, 2017

\begin{abstract}
Summary
This study aimed at examining the secretion activity of steroid hormones progesterone and $17 \beta$-estradiol by porcine ovarian granulosa cells after addition of green tea extract. Granulosa cells were incubated with green tea extract (at doses of $0.01,0.1,1$, 10 and $100 \mu \mathrm{g} \cdot \mathrm{ml}^{-1}$ ). Another set of cells were incubated with green tea extract at the above doses along with additional supplementation of follicle stimulating hormone (FSH) at $10 \mu \mathrm{g} \cdot \mathrm{ml}^{-1}$. Release of hormones by granulosa cells was assessed by EIA after $24 \mathrm{~h}$ exposure. Secretion of steroid hormones was not affected either by green tea extract alone or after FSH supplementation with green tea extract. Results indicate that ovarian steroidogenesis is not affected by green tea under conditions used in the experiment.
\end{abstract}

\section{Key words}

Green tea • Ovarian granulosa cells • Anti-microbial activity • FSH - Steroid hormones

\section{Corresponding author}

A. Kolesarova, Department of Animal Physiology, Faculty of Biotechnology and Food Sciences, Slovak University of Agriculture in Nitra, Nitra 949 76, Slovak Republic. E-mail: Adriana.Kolesarova@uniag.sk

Green tea (Camellia sinensis L., Theaceae) is a widely consumed beverage all over the world. Healthpromoting activities of green tea extract have been attributed to flavonoid-like polyphenols known as catechins (Khan and Mukhtar 2007). The unique property of green tea catechins has the potential to improve reproductive health, including the quality of male and female gametes (Roychoudhury et al. 2017). Ovarian granulosa cells play a central role in steroidogenesis, which is critical for female reproduction (Harvey et al. 2009). Steroid hormone secretion by ovarian granulosa cells ensures a receptive environment for the implantation and development of the early embryo (Albertini et al. 2003). The aim of this in vitro study was to examine the steroid hormone (progesterone, 17ß-estradiol) secretion by porcine ovarian granulosa cells after addition of green tea extract and green tea extract + follicle stimulating hormone (FSH). Briefly, $50 \mathrm{~g}$ plant materials (packaged leaves of Chun Mee green tea of Chinese origin) were grounded mechanically into fine powder and were extracted with $350 \mathrm{ml}$ distilled water by boiling under reflux for $30 \mathrm{~min}$. The extract was filtered and evaporated to dryness to yield the dry extract (yield $\sim 50 \%$ ) (Chatterjee et al. 2012). Just before the addition to the cells, extract was dissolved first in DMSO (concentration $10 \mathrm{mg} \cdot \mathrm{ml}^{-1}$ ) and then in culture medium. The maximal concentration of DMSO in culture (and added to control) was $0.1 \%$. Ovarian granulosa cells were collected from the follicles $(3-5 \mathrm{~mm})$ of prepubertal gilts according to EU and Slovak guidelines for animal care, manipulation and use, were washed in sterile DMEM/F12 1:1 medium (BioWhittaker, Verviers, Belgium), and resuspended in the same medium supplemented with $10 \%$ fetal bovine 
serum (FBS, BioWhittaker, Verviers, Belgium) with $1 \%$ antibiotic-antimycotic solution (Sigma, St. Louis, MO,

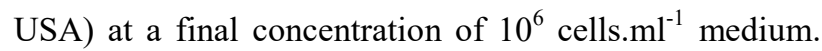
Granulosa cell suspension ( $1 \mathrm{ml} /$ well) was dispensed in 24-well culture plates (Nunc, Roskilde, Denmark) and incubated at $37^{\circ} \mathrm{C}$ and $5 \% \mathrm{CO}_{2}$ in humidified air until $60-75 \%$ confluent monolayer was formed (3-5 days), at that point medium was renewed. Further culture was performed in $1 \mathrm{ml}$ culture medium in 24-well culture plates (Kolesarova et al. 2012, Packova et al. 2015, Roychoudhury et al. 2015). After medium replacement experimental cells were cultured for $24 \mathrm{~h}$ without (control) or with green tea extract (at doses of $0.01,0.1$, 1,10 and $100 \mu \mathrm{g} \cdot \mathrm{ml}^{-1}$ ), and green tea extract (at doses of 0.01, 0.1, 1, 10 and $100 \mu \mathrm{g} . \mathrm{ml}^{-1}$ ) + FSH (Sigma Aldrich, Steinheim, Germany) at $10 \mu \mathrm{g} \cdot \mathrm{ml}^{-1}$. Concentrations of progesterone and $17 \beta$-estradiol were determined in duplicate in the incubation medium by EIA (Packova et al. 2015, Roychoudhury et al. 2014). All EIAs were validated for use in samples of culture medium. For progesterone, intra- and interassay coeficients of variation did not exceed $4 \%$ and $9.3 \%$, respectively. For $17 \beta$-estradiol, intra- and interassay coeficients of variation did not exceed $9 \%$ and $10 \%$, respectively. Each treatment group was represented by 4 wells. Assays for hormone concentration in the incubation medium were performed in duplicates. Each experiment was performed thrice. Significant differences between the experiments were evaluated using one-way ANOVA followed by paired Wilcoxon-Mann-Whitney test (Systat Software, GmbH, Erkhart, Germany). Differences from control at $\mathrm{P}<0.05$ were considered significant. In culture, granulosa cells formed a monolayer and secreted progesterone and $17 \beta$-estradiol. Release of these steroid hormones was not affected by green tea extract at the doses used. FSH supplementation to green tea extract showed an increasing trend of progesterone and $17 \beta$-estradiol release in comparison to green tea alone, however, the differences were not statistically significant (Figs 1 and 2). In an earlier study, treatment with 10 ng. $\mathrm{ml}^{-1}$ ovine FSH did not affect estradiol release although progesterone secretion was stimulated by bovine granulosa cells (Wrathall and Knight 1993). Experimental granulosa cells were suitable for testing and analysis of green tea extract as they formed cell monolayer and released of hormones into the culture medium. Epigallocatechin-3-gallate (EGCG), a major green tea catechin constituting more than $50 \%$ of total catechins (catechins make up approx. $40 \%$ of dried tea extract) was able to increase progesterone release at a dose of $10 \mu \mathrm{g} \cdot \mathrm{ml}^{-1}$, but not at higher doses. On the contrary, another study noted inhibition of progesterone as well as estradiol secretion by granulosa cells at 5 and $50 \mu \mathrm{g} . \mathrm{ml}^{-1}$ EGCG (Basini et al. 2005). These differences could be explained by the differences source of ovarian cells, for example, ovaries from mature pigs versus prepubertal pigs, as used in our study. Variation in the composition of green tea may be another factor behind the different study results obtained from separate studies.

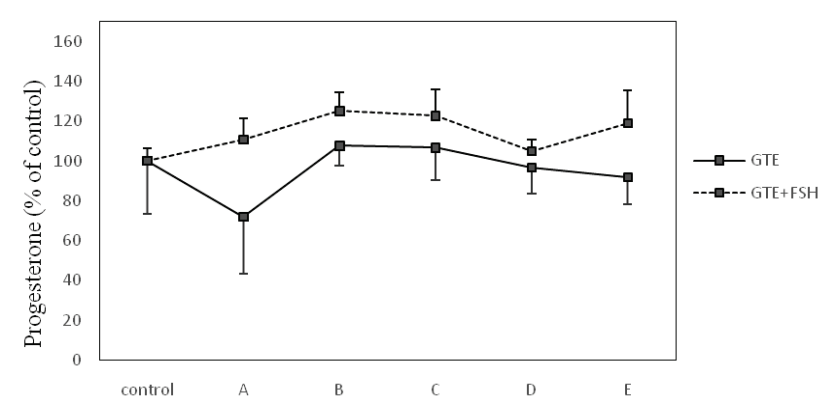

Fig. 1. Progesterone release by cultured porcine ovarian granulosa cells after addition of: (A) green tea extract (GTE), and (B) green tea extract + FSH. EIA after $24 \mathrm{~h}$ of culture. Each bar represents the mean $( \pm \mathrm{SD}$ ) progesterone $\%$ of control.

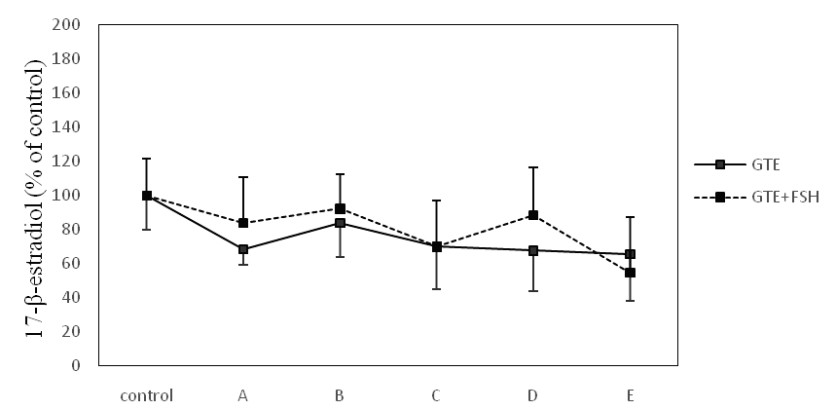

Fig. 2. 17ß-estradiol release by cultured porcine ovarian granulosa cells after addition of: (A) green tea extract (GTE), and (B) green tea extract + FSH. EIA after $24 \mathrm{~h}$ of culture. Each bar represents the mean ( $\pm \mathrm{SD}$ ) progesterone $\%$ of control.

The composition of green tea depends on factors such as geographical location (climate, soil), agricultural practices (fertilizers, deadheading) and the properties of the plant itself (variety, age of the leaf, and position of the leaf on the harvested shoot) (Cabrera et al. 2006). Ten-day infusion green tea extract showed reproductive improvement in estradiol valerate-induced polycystic ovarian syndrome in rats, including decrease in the levels of serum luteinizing hormone $(\mathrm{LH})$ and testosterone, but FSH levels remained unchanged (Ghafurniyan et al. 2015). In adult albino male rats, serum levels of 
gonadotropic hormones FSH and LH as well as steroid hormone testosterone were reduced by green tea extract after 26 days of treatment in vivo (Das and Karmakar 2015). Earlier in vivo study on albino male rats for 26 days reported inhibition of testicular delta(5)3beta-and 17beta-hydroxysteroid dehydrogenase, including serum testosterone and LH levels but FSH levels did not change (Chandra et al. 2011). In the present study, the inability of FSH to stimulate the release of either progesterone or estradiol by porcine ovarian granulosa cells may reflect a paucity of functional FSH receptors (Wrathall and Knight 1993).

In conclusion, our results indicate that used doses of green tea extract did not affect steroid secretion by ovarian granulosa cells but FSH supplementation to green tea extract showed an increasing trend of progesterone and $17 \beta$-estradiol release. Although these data contribute to new insights regarding the action of green tea extract, it is necessary to examine the individual steps of steroidogenesis in ovarian cells.

\section{Conflict of Interest}

There is no conflict of interest.

\section{Acknowledgements}

This work was financially supported by the Ministry of Education, Science, Research and Sport of the Slovak Republic projects no. VEGA, 1/0039/16, KEGA 011SPU-4/2016, Slovak Research and Development Agency, APVV-0304-12, APVV-15-0543 and European Community under project no. 26220220180: Building Research Centre "AgroBioTech".

\section{References}

ALBERTINI DF, BARRETT SL: Oocyte somatic cell communication. Reprod Suppl 61: 49-54, 2003.

BASINI G, BIANCO F, GRASSELLI F: Epigallocatechin-3-gallate from green tea negatively affects swine granulosa cell function: Domest Anim Endocrinol 28: 243-256, 2005.

CABRERA C, ARTACHO R, GIMENEZ R: Beneficial effects of green tea - a review: J Am Coll Nutr 25: 79-99, 2006.

CHANDRA AK, CHOUDHURY SR, DE N, SARKAR M: Effect of green tea (Camellia sinensis L.) extract on morphological and functional changes in adult male gonads of albino rats. Indian J Exp Biol 49: 689-687, 2011.

CHATTERJEE P, CHANDRA S, DEY P, BHATTACHARYA S: Evaluation of anti-inflammatory effects of green tea and black tea: a comparative in vitro study. J Adv Pharm Technol Res 3: 136-138, 2012.

DAS SK, KARMAKAR SN: Effect of green tea (Camellia sinensis L.) leaf extract on reproductive system of adult male albino rats: Int J Physiol Pathophysiol Pharmacol 7: 178-184, 2015.

GHAFURNIYAN H, AZARNIA M, NABIUNI M, KARIMZADEH L: The effect of green tea extract on reproductive improvement in estradiol valerate-induced polycystic ovary polycystic ovarian syndrome in rat. Iran J Pharm Res 14: 1215-1233, 2015.

HARVEY CN, ESMAIL M, WANG Q, BROOKS AI, ZACHOW R, UZUMCU M: Effect of the methoxychlor metabolite HPTE on the rat ovarian granulosa cell transcriptome in vitro. Toxicol Sci 110: 95-106, 2009.

KHAN N, MUKHTAR H: Tea polyphenols for health promotion. Life Sci 81: 519-533, 2007.

KOLESAROVA A, CAPCAROVA M, MARUNIAKOVA N, LUKAC N, CIERESZKO RE, SIROTKIN AV: Resveratrol inhibits reproductive toxicity induced by deoxynivalenol. J Environ Sci Health A Tox Hazard Subst Environ Eng 47: 1329-1334, 2012.

PACKOVA D, CARBONELL-BARRACHINA AA, KOLESAROVA A: Ellagitannins - compounds from pomegranate as possible effector in steroidogenesis of rabbit ovaries. Physiol Res 64: 583-585, 2015.

ROYCHOUDHURY S, DETVANOVA L, SIROTKIN AV, TOMAN R, KOLESAROVA A: In vitro changes in secretion activity of rat ovarian fragments induced by molybdenum. Physiol Res 63: 807-809, 2014.

ROYCHOUDHURY S, MASSANYI P, SLIVKOVA J, FORMICKI G, LUKAC N, SLAMECKA J, SLAMA P, KOLESAROVA A: Effect of mercury on porcine ovarian granulosa cells in vitro. J Environ Sci Health A Toxicology Hazard Subst Environ Eng 50: 839-845, 2015.

ROYCHOUDHURY S, AGARWAL A, VIRK G, CHO CL: Potential role of green tea catechins in the management of oxidative stress-associated infertility. Reprod Biomed Online 34: 487-498, 2017.

WRATHALL JH, KNIGHT PG: Production of immunoactive inhibin by bovine granulosa cells in serum-free culture: effects of exogenous steroids and FSH. Domest Anim Endocrinol 10: 289-304, 1993. 